\title{
A disparada rumo ao capitalismo
}

JOHN KENNETH GALBRATTH

$\mathrm{Q}$ ue os últimos meses foram marcados pelas maiores transformaçóes dos nossos tempos é uma questáo sobre a qual năo preciso insistir. O que se tem revelado apenas um pouco menos evidente é o fluxo de conselhos econômicos que têm cruzado as fronteiras nacionais durante esses meses. No consenso geral, tendo falhado o comunismo, triunfou o capitalismo. E daí a conclusão: do alto sacerdócio do capitalismo deve agora partir a orientaçáo, na verdade a intimaçáo, acerca do que os países previamente afligidos devem ter $\mathrm{e}$ fazer. Quem poderia estar melhor qualificado para prestar conselhos e orientaçáo do que os mais inflexíveis expoentes do bem-sucedido sistema?

Grande parte desses conselhos tem saído de nosso próprio país. Nós, não surpreendentemente, abrigamos e damos a palavra a um número considerável de arquiexpoentes da livre-empresa. Tem contribuído para isso o fato de que os conselhos que emanam destas margens sáo maravilhosamente baratos, quando comparados com a ajuda mais substancial que muitos de nós temos reclamado como forma de facilitar essa enorme transição.

No meu modo de ver, boa parte, talvez a maioria, dos conselhos agora oferecidos aos estados da Europa Central e do Leste procedem de uma visão das assim chamadas economias capitalistas ou de livre-empresa, que não têm relação alguma com suas realidades. Nem essas economias teriam sobrevivido se o tivessem. O que se oferece é uma construçáo ideológica que não existe senão nas mentes $\mathrm{e}$, notoriamente, nas esperanças dos doadores. Não tem relação alguma com a realidade; é o que noutra oportunidade chamei de ideologia primitiva.

Esses conselhos têm dois aspectos. Alguns são de pessoas que já há bastante tempo lamentam as concessóes que as economias ocidentais tềm feito à questão social - ao estado do bem-estar - $\mathrm{e}$ à assistência pública aos pobres; ao papel essencial e crescente dos serviços públicos; aos sindicatos; às medidas destinadas a obter maior igualdade na distribuiçáo das rendas; e a uma mais ampla responsabilidade pós-keynesiana quanto ao desempenho efetivo do sistema econômico como um todo. Elas não gostam do que vêem em casa; assim, isso naturalmente não faz 
parte de suas recomendaçóes para os países que agora emergem do comunismo. E, é claro, não deixam de ter seu público por lá: na economia e na política, tal como na religiăo, o recém-convertido é freqüentemente $o$ mais ardente em sua crença.

O segundo e correlato aspecto do fluxo de conselhos que presentemente atinge os países agora em transição é sua aceitaçăo negligente da - ou mesmo condenação à - privaçăo humana, desemprego, inflação e níveis de vida desastrosamente degradados. Isto chega mesmo a ser encarado como terapia necessária: da experiência do desemprego e da fome brotará uma nova e revigorada ética trabalhista, uma força de trabalho ávida pela disciplina da livre-empresa. A cada um, segundo suas habilidades, de cada um, segundo suas necessidades. Num ponto de vista ardentemente expresso, que ouvi há poucos dias de um consultor de negócios - recém chegado da Polônia, tal privaçáo - desemprego, baixos salários - levará investidores e empresários estrangeiros a virem em resgate no futuro. Somente uns poucos anos de sofrimento e tudo entáo ficará bem. Isso, escolho minhas palavras com cuidado, é loucura. Nada ao longo dos séculos tem sido pregado com mais insistência do que a recompensa social das privaçóes por aqueles que não terão que sofrê-las.

Aos pobres da Bíblia foi dito que, diversamente dos ricos, eles teriam acesso fácil ao Céu. De modo mais simples, boa parte desses conselhos consiste em propor a substituição de um sistema econômico que funciona precariamente por absolutamente nenhum.

O sistema econômico que os países da Europa Central e do Leste vêem no Japão e no Ocidente não é o capitalismo em sua forma prístina e primitiva. É um sistema profundamente modificado por melhorias nos serviços sociais, rendas subsidiadas e controles públicos. É devido a esses fatores que o sistema sobreviveu. Na Grã-Bretanha, a sra. Thatcher, e até há pouco tempo, nos Estados Unidos, o sr. Reagan e seus acólitos, de fato, pintaram-se a si mesmos como arquiexpoentes de um capitalismo sem peias. Na realidade, eles devem, ou deveram, seu prestígio a geraçóes precedentes de líderes voltados a causas sociais, que tornaram seus cidadãos mais seguros e confortáveis econômica e socialmente - e agora, em seus votos, conservadores. Reagan e Thatcher foram, ou são, preservados em seus cargos porque, na prática, sua retórica da livreempresa provou-se quase inteiramente inalterada na ação. Tivesse Reagan desferido, durante o seu primeiro mandato, um sério ataque ao sistema de benefícios sociais - pensóes para os idosos, compensaçóes para os desempregados, programas de saúde para os desfavorecidos, subsídios para os agricultores - a sua presidência teria chegado abrup- 
tamente ao fim em janeiro de 1985.

$\mathrm{Na}$ verdade, nem se pode dizer que as tarefas sociais do capitalismo tenham sido cumpridas. Grande parte de nossa gente ainda vive fora do sistema: ouvem falar muito de democracia mas năo crêem que vale a pena votar. Como disse noutra oportunidade, é uma realidade sombria, mas totalmente inegável, que ninguém em busca de uma vida melhor iria sensatamente se mudar de Berlim Oriental para o South Bronx. Nem mesmo em busca de liberdade, pois nada reprime tanto a liberdade como uma efetiva falta de dinheiro, comida e um lugar para morar. A administração de Bush, segundo relatórios recentes, está considerando a hipótese de enviar especialistas à Uniâo Soviética para orientar na criaçăo das várias instituições do capitalismo, $\mathrm{e}$ aí se incluem pretensos especialistas na construçáo de moradias particulares Eles, presumivelmente, irăo relatar como esta indústria falhou virtualmente em todos os países capitalistas, na tentativa de criar abrigos adequados para os pobres, e deixou milhóes de pessoas sem teto nos Estados Unidos. Com tudo o mais, a política de nosso tempo tem o seu próprio humor negro.

Retorno a meu ponto principal: o que se está vendo no Ocidente a partir do Leste do que foi uma vez o Muro năo é o capitalismo tradicional. É uma ainda imperfeita democracia social. De modo bastante real, tanto no Oriente como no Ocidente, nossa tarefa é a mesma: buscar e encontrar o sistema que combine o melhor da economia de mercado com o melhor da motivaçăo social.

Não há nesta busca regras todo-poderosas pelas quais se guiar. Para as naçóes agora em transiçăo, eu recomendaria, é claro, a volta ao mercado de serviços e bens de consumo menos essenciais. Neste ponto, isto é por si mesmo bastante evidente, o sistema de planejamento e comando da experiência passada náo funcionou. A demanda de consumo é variada, instável e somente o mercado transmite adequadamente sua mensagem do produtor aos consumidores. A ação aqui năo precisa ser brusca; deve ocorrer quando gerentes e empresários corretos estiverem disponíveis e instituiçóes públicas financeiras forem criadas para financiar a transferência de propriedade ou a criaçáo de novas firmas. Como toda transformação, deve partir de reflexóes, não de fórmulas. É à necessidade por bens de consumo que a ajuda econômica, que irei mencionar mais tarde, deve fundamentalmente se voltar.

Para alimentação e moradia, eu preveria um papel mais prolongado e constante para o Estado. Qualquer súbita e ampla alteração no preço dos alimentos essenciais e nos aluguéis, com certeza, vai provocar inquietude e despertar ressentimentos, como já se mostrou evidente no caso dos alimentos na Polônia e URSS. Subsídio público neste ponto 
não é algo incomum. É normal. Os Estados Unidos, todos os países da CEE e o Japão subsidiam seus suprimentos de comida a um elevado custo público e, como observei, em lugar algum o capitalismo proporciona moradias adequadas $\mathrm{e}$ acessíveis aos cidadáos de baixa renda.

Eu também recomendaria medidas práticas para que a agricultura e sobretudo a comercializaçáo da maioria dos produtos agrícolas retornasse ao sistema de preços. É uma questão mundialmente observada $e$ provada que a agricultura trabalha melhor quando sob o comando automotivado e frequientemente auto-explorativo do agricultor privado. Não desconheço as dificuldades de sair do mundo mais confortável das fazendas coletivas e estatais. Não tenho dúvidas, no entanto, de que isso é necessário. Mas a moderação, não a ideologia, deve novamente ser a regra. Mais do que uma cortês precauçáo está envolvida aqui. Os produtores agrícolas trabalham bem e investem bem somente quando têm garantia sobre eventuais preços e receitas. A agricultura nos Estados Unidos teve, no último meio século, enormes ganhos em produtividade, superando em muito os da indústria. Isso ocorreu em parte porque os agricultores puderam investir com retorno garantido pelo governo.

Quanto à grande empresa industrial ou comercial, que é a peça central da economia capitalista ou socialista moderna, a questão da propriedade última náo é tão importante. Nos países ocidentais e no Japão há firmas com bom desempenho sob ambos os modos de propriedade, privada ou estatal. Na Suíça, onde vivo uma parte do tempo, viajamos numa estrada de ferro de propriedade pública, falamos num telefone de propriedade pública. Nosso apartamento é segurado pela municipalidade. Os agricultores em nossa vizinhança têm garantia de renda adequada às suas necessidades. Uma boa casa é um direito humano. A loja, excepcionalmente boa que fornece nossos alimentos e muitas outras coisas, é uma cooperativa. Nossa conta bancária é com um banco de propriedade pública. De fato, não podemos cortar uma árvore, provavelmente nem mesmo plantar uma, sem permissáo do poder público. Os adoráveis prados alpinos são preservados por fazendeiros que são subsidiados pelo Estado para mantê-los. Os suíços, não obstante, são célebres por seu diligente apego à livre-empresa.

Nos Estados Unidos nossas ferrovias faliram sob comando privado e têm sido parcialmente recuperadas sob a administração pública. Falências privadas em nossas instituiçóes financeiras estáo sendo agora recuperadas pelo Estado ao custo de centenas de bilhóes de dólares. A frase sob o controle do governo aparece diariamente em nossas páginas de finanças. Deixando de lado o caso excepcional e bastante criticado daqueles que lutam arriscadamente pelo controle das corporaçóes, os acio- 


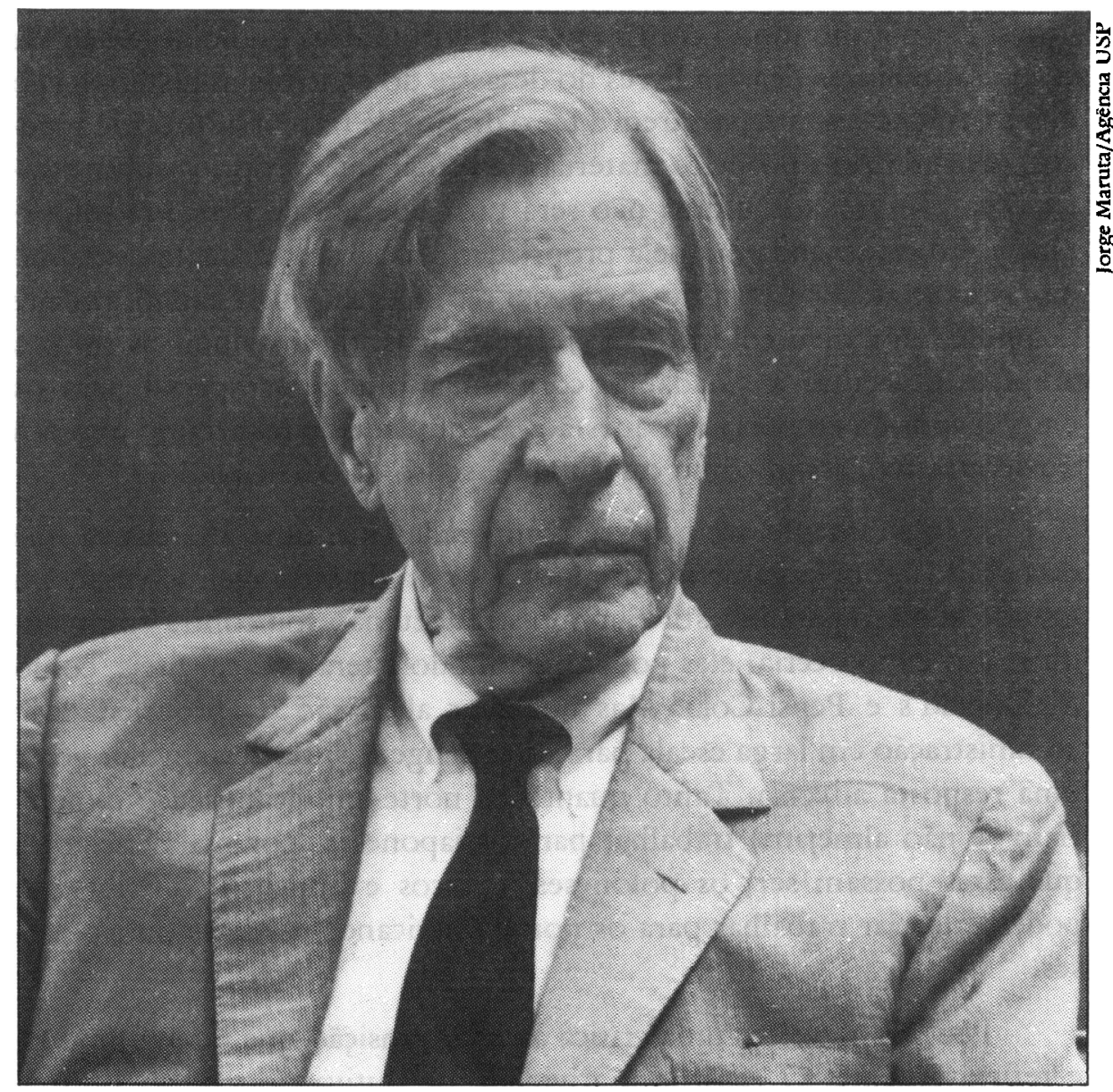

John Kenneth Galbraith fez a Conferência do Mês de novembro de 1986 do IEA sobre "Controle de Armamentos e Poder Militar"

nistas - proprietários das grandes firmas do capitalismo moderno permanecem dispersos $\mathrm{e}, \mathrm{em}$ sua maioria, desconhecidos. Eles náo têm poder sobre a administração profissional que indica os diretores que, presumivelmente, irão controlar suas operaçóes. Isto, na frase do falecido James Burnham, um notório conservador, foi a Revolução Gerencial. No capitalismo moderno, os gerentes, e não os capitalistas, săo o poder decisivo. E na moderna economia capitalista madura, ressalto, não é com o poder que deveríamos nos preocupar, mas com a incompetência.

O que importa - minha recomendação neste ponto retrocede a uma antiga observação e experiência na Índia - é dar à empresa autoridade, e recompensas decorrentes, sobre seu próprio desempenho. Não deve estar ligada a ou ser controlada por um ministro de Estado; náo deve haver o que na Índia chamei de socialismo postal Nenhuma pessoa normal trabalha bem quando um outro tem total autoridade sobre suas 
açōes. Do mesmo modo com a empresa corporativa ou de negócios. Se empresas maiores ficarem livres do desastre do controle ministerial, isto é, burocrático e assim passarem a ter o direito de fixar seus próprios preços, procurar seus próprios materiais, e fechar seus próprios subcontratos, sua propriedade última não será uma questáo de primeira importância. Eu recomendaria que a propriedade fosse amplamente distribuída e sou atraído pela prática proposta na Polônia, que é enfaticamente defendida por meu colega Prof. Jeffrey Sachs, de distribuir as fraçōes amplamente entre a cidadania, com uma vantagem especial para os empregados da empresa em questão. A eqüidade de tal arranjo tem um óbvio atrativo, assim como o resultante senso de participaçáo.

É seguramente aceitável se comparada com uma alternativa que está sendo agora largamente discutida, que é a de estrangeiros virem em grande número para investir e administrar. Eu náo sou contra empreendimentos em parceria; eles podem, de modo lateral, serem úteis, como McDonald's e Pepsi-Cola. Mas qualquer alienaçáo da propriedade e administraçáo em larga escala para os estrangeiros iria certamente gerar uma resposta adversa. Tanto quanto os norte-americanos nảo almejariam (e nāo almejam) trabalhar para os japoneses, por mais eficientes que estes possam ser, os poloneses, tchecos e húngaros dificilmente podem almejar trabalhar para os norte-americanos, alemães ou japoneses.

Isto não deve ser uma crítica àquela transição que é feita gradual e reflexivamente. $O$ retorno à atividade produtiva normal na Europa Ocidental após a Segunda Guerra Mundial, uma tarefa menos complexa do que a que têm pela frente a URSS e a Europa Oriental, levou grande parte de uma década. $\mathrm{Na}$ Grã-Bretanha passaram-se sete anos antes que a libra esterlina fosse plenamente conversível, e o racionamento de comida e controle associado de preços também se prolongaram por um bom tempo. A ação repentina, mais uma vez, é para aqueles que eles próprios não sofrem, não pensam antes de agir, que procedem pela fórmula, não pelo fato. Somente se se der tempo haverá tempo para a reflexāo - a reflexão que está sintonizada com resultados pragmáticos e não com a ideologia primitiva.

Até agora, enfatizei uma açăo cuidadosa, livre de paixóes e fantasias ideológicas, como o desígnio necessário para reduzir o desespero e sofrimento humanos. É, também, a trilha que minimiza o impacto de conflitos nacionais, étnicos, raciais e religiosos; pois as agruras econômicas e privaçóes, acima de tudo, alimentam tais conflitos. $O$ bem-estar econômico é o grande solvente para tais paixóes. E nada, por sua vez, é tão prejudicial ao bem-estar econômico como lutas civis e religiosas. E 
um dos fatos tristes e inegáveis do nosso tempo que a pobreza produz conflito e o conflito por sua vez aprofunda a pobreza. A reivindicação mais orgulhosa da democracia social, em suas variadas terminologias, do liberalismo nos Estados Unidos ao socialismo democrático na Europa, é a de que se mantêm, acima das paixões, preconceitos e conflitos nacionais, étnicos e religiosos. E a maior de suas armas é a promessa de bem-estar econômico - o bem-estar, para repetir, do qual a tranqüilidade depende e pela qual é servido.

Há mais um ponto a ser acentuado. As tarefas econômicas que aqui delineei requerem, para serem cumpridas, inteligência e discrição. O despertar de paixóes étnicas, raciais ou nacionais não requer nada disso. Qualquer um com voz mais do que com cérebro pode liderar uma cruzada contra minorias lingüísticas, étnicas ou religiosas na Europa: o mesmo náo ocorre com as tarefas de reconstruçáo econômica que agora se têm pela frente.

Há, ainda, uma mais longínqua tradiçăo de democracia social e consciência social pela qual me bato. Esta grande transição deve ser encarada como uma que diz respeito a todos nós, na qual todos devemos participar. Nesse aspecto, não sou inteirametne otimista com relação ao nosso próprio governo; ele retrocedeu profundamente nos últimos tempos à economia e à política do comodismo. Muitos mencionaram a grande oportunidade para um novo Plano Marshall; a necessidade persiste. Ao invés disso, como observei, oferecemos retórica e conselhos que se repartem entre o dano e a irrelevância. ( $\mathrm{E}$, como táo freqüentemente, entre graves dificuldades presentes e potenciais, ouvimos o pedido de austeridade do FMI.) Mas rogo a todos os meus correligionários, aqui e na Europa Ocidental, que resistam ao desânimo e se unam para estender aos países do Leste europeu os tipos de programas que nós nos Estados Unidos oferecemos em 1948. Isto, de parte dos norteamericanos, não é uma esperança isolada nem mesmo, de uma minoria. $\mathrm{E}$, talvez com este exemplo, os norte-americanos em geral e nosso governo em particular se postem novamente à altura dos desafios de seu tempo.

Jolnn Kenneth Galbraith é economista e professor da Universidade de Harvard, EUA. Foi embaixador dos Estados Unidos da India, no governo Kennedy, de 1961 a 1963. Entre seus vários livros, destacam-se o clássico The age of uncertainty (1977, traduzido no Brasil pela Editora Pioneira sob o título de $A$ era da incerteza), Economics and the public purpose (1974) e Money: whence it come where it went (1975).

Texto publicado com permissão de The Neñ York Review (Volume XXXVIII, Número 16, 1990).

Tradução de Alberto Alexandre Martins. O original em inglês encontra-se à disposị̧ăo do leitor no IEA para eventual consulta. 